\title{
Teaching and learning reflection in MPA programs:
}

\section{towards a strategy}

\author{
Frans-Bauke van der Meer \\ Peter Marks
}

Erasmus University Rotterdam, The Netherlands

Corresponding author: Frans-Bauke van der Meer, Department of Public Administration, Erasmus University, P.O. Box 1738, 3000 DR Rotterdam, The Netherlands. E-mail:

f.b.vandermeer@fsw.eur.nl 


\section{Teaching and learning reflection in MPA programs:}

\section{towards a strategy}

\section{Introduction}

Reflection is core business of MPA graduates. They should not be merely apply public administration theories and methods in standardized ways but always think critically about what they do and why. Therefore, they should develop a critical attitude with respect to PA research and theory as well as to real life definitions of problems and of solutions. Moreover they should be able to make sensible situated connections between 'theory' and 'praxis' and critically and creatively derive new modes of professional action from these. They should be able to recognize and deal with uncertainty and ambiguity (Cunliffe \& Jun, 2005). However, teaching staff, at least in our program at Erasmus University (presented below), feels that for many students it is difficult to meet these standards. Some students seem to use methods, models and theories quite instrumentally and without reflection.

Perhaps personal characteristics or attitudes of students play a role in this state of affairs. But there may also be factors in the program that contribute to meager results with respect to reflection e.g. in the way teachers teach, or in the requirements for papers and exams. This paper tries to identify some of these factors and related mechanisms, to analyze these and to find ways to enhance both the teaching and the learning of reflection.

Section 2 discusses what reflection is and why teaching and learning it is essential in postexperience MPA programs. Then we describe what we actually do in our program at Erasmus University Rotterdam to enhance reflection and which difficulties and limits teachers experience in doing so (section 3). In section 4 options to improve are discussed and finally in section 5 a strategy to involve both teachers and students in the improvement process is outlined. 


\section{Reflection}

A Post-experience MPA program is a trajectory of professionalization for the students involved. Hardly any of the graduates of these programs are choosing an academic career. However, they want to be educated at an academic level because the complexity of their professional contexts requires this, as do jobs they want to acquire. Hence, as graduates of an academic program, they should on graduation be able to function on an academic level in their professional contexts. This means that they do not only have to 'know' relevant PA academic theories and methods, but also to 'use' these in sensible ways in their professional practice (see contribution by Quinn to this special issue). Given the complex, ambiguous and multiple nature of many public administration issues (even the definition of what is an issue is not straightforward), this is not an instrumental activity that can be more or less standardized or programmed. It requires critical thinking, not transferring, but translating (Adriansen \& Knudsen, this special issue). Cunliffe \& Jun (Cunliffe \& Jun, 2005) make a distinction between 'reflectivity' on the one hand and 'reflexivity' (with an $\mathrm{x}$ ) on the otheri. The first concept refers to sensible application of concepts, theories and methods, and the second to critically considering concepts, theories and methods as such, as well as recognizing and considering ambiguities in 'real life' and in linking scientific notions to real life practice. Reflexivity implies the use of social constructionist notions: how are terms, concepts, practices, problem definitions, solutions, theories, strategies, ideologies etc. constructed in ongoing social interaction? How do these social constructions influence ongoing interaction, identities, expectations, judgments, etc.? Can these processes be deconstructed to facilitate a reflexive dialogical praxis (Cunliffe, 2002) that enables new sense making processes?

Reflection (we use the term to capture both reflectivity and reflexivity) can be focused on different objects, each of which give rise to specific reflective and reflexive activities (Cf. Smith, 2011: 216). Inspired by Smith we developed the inventory of modes and objects of reflection presented in table 1. We think this captures the spectrum of relevant foci for reflection. 


\begin{tabular}{|c|c|c|}
\hline & \multicolumn{2}{|c|}{ Modes of reflection } \\
\hline Objects of reflection & Reflectivity & Reflexivity \\
\hline Theories & $\begin{array}{l}\text { 1. understand theories and } \\
\text { their relevance } \\
\text { 2. explain theories and de- } \\
\text { scribe their applicability } \\
\text { 3. working with concepts } \\
\text { (e.g. use them in an essay) }\end{array}$ & $\begin{array}{l}\text { 14. identify (tacit) presupposi- } \\
\text { tions } \\
\text { 15. critical review of theories } \\
\text { (e.g. based on empirical re- } \\
\text { search, observations, or own } \\
\text { experience) } \\
\text { 16. playing with concepts and } \\
\text { presuppositions }\end{array}$ \\
\hline Scientific methods & $\begin{array}{l}\text { 4. explain methods and their } \\
\text { applicability } \\
\text { 5. make a sensible research } \\
\text { design } \\
\text { 6. apply methods } \\
\text { 7. analyze data }\end{array}$ & $\begin{array}{l}\text { 17. identify methodical presup- } \\
\text { positions } \\
\text { 18. develop a research strategy } \\
\text { 19. critical discussion of research } \\
\text { results }\end{array}$ \\
\hline $\begin{array}{l}\text { Diagnosis (definitions } \\
\text { of situation, of prob- } \\
\text { lems) }\end{array}$ & $\begin{array}{l}\text { 8. } \text { analyze situations/ prob- } \\
\text { lems (using theo- } \\
\text { ries/concepts/methods) }\end{array}$ & $\begin{array}{l}\text { 20. identify and deconstruct } \\
\text { problem definitions } \\
\text { 21. analyze the role of problem } \\
\text { definitions in the process } \\
\text { 22. creatively develop sensible } \\
\text { alternative problem defini- } \\
\text { tions }\end{array}$ \\
\hline Policy (solutions and & 9. use theory and results of & 23. identify and critically review \\
\hline
\end{tabular}




\begin{tabular}{|c|c|c|}
\hline & \multicolumn{2}{|c|}{ Modes of reflection } \\
\hline Objects of reflection & Reflectivity & Reflexivity \\
\hline $\begin{array}{l}\text { definitions of solu- } \\
\text { tions) }\end{array}$ & $\begin{array}{l}\text { empirical research to de- } \\
\text { velop policy advice }\end{array}$ & $\begin{array}{l}\text { presuppositions of policies } \\
\text { 24. identify and deconstruct actor } \\
\text { definitions of 'solution' } \\
\text { 25. creatively develop sensible } \\
\text { alternative 'solutions' }\end{array}$ \\
\hline $\begin{array}{l}\text { Behavior (routines, } \\
\text { procedures, manage- } \\
\text { ment, strategies) }\end{array}$ & $\begin{array}{l}\text { 10. Explain behaviors and their } \\
\text { impacts by applying theo- } \\
\text { ries } \\
\text { 11. Develop (management) } \\
\text { strategies by applying the- } \\
\text { ories }\end{array}$ & $\begin{array}{l}\text { 26. Identify and critically review } \\
\text { presuppositions of strategies } \\
\text { 27. Critically review accounts of } \\
\text { (change in) strategies and } \\
\text { behavior patterns }\end{array}$ \\
\hline $\begin{array}{l}\text { Own professional } \\
\text { functioning (profes- } \\
\text { sional self-reflection) }\end{array}$ & 12. sensibly use PA toolkit & $\begin{array}{l}\text { 28. Identify self-evidences and } \\
\text { presuppositions in own be- } \\
\text { havior } \\
\text { 29. Critically assess dynamics } \\
\text { and impacts of own actions }\end{array}$ \\
\hline Reflection & $\begin{array}{l}\text { 13. learn to translate scientific } \\
\text { knowledge to real-life set- } \\
\text { tings }\end{array}$ & 30. learn (to organize) reflexivity \\
\hline
\end{tabular}

Table 1: Foci of reflection

The first mode of reflective application of theories and instruments is not self-evident. Even though some of the first thirteen elements are easier to learn for the studentsii, it is not selfevident that they learn all elements or that they do not fall back to their more or less instru- 
mental approach to PA theories. In other words, how do students learn it? How well are PA programs designed to train and internalize it?

The second mode, reflexivity, is even less self-evident. Students find it difficult to acquire the reflexive elements and easily take things at face value. How do we learn to become reflexive and how do we learn to remain reflexive? This seems to involve continuous learning processes that students should be able and willing to realize and engage in during the program and after they have finished it.

All in all, certain elements in the two modes will be learned by students, while others will remain obscure. An MPA program should try to help students in learning all elements. Question then is of course, how MPA programs can help to develop this competence and attitude.

\section{Teaching reflection}

The central question of this paper is how the reflective practices discussed can be stimulated, supported and trained in MPA programs. In this section we discuss what we actually do in this respect in the program at Erasmus University Rotterdam, why and with what results. In the next section we discuss options for improvement.

\section{Reflection in the Erasmus University MPA program}

Since 2003 Erasmus University Rotterdam has a two-year MPA program. There are 7 to 8 contact hours per week, delivered on two evenings per week and incidentally during day time. Students have at least two and on average five or six years of relevant professional experience and have completed a higher vocational training in a previous stage of their life. Each year 50 to 60 students starts with the program and about 45 graduate. The program is specifically designed for practitioners (Van der Meer \& Ringeling, 2010). It consists of 10 modules (60 ECTS) in the first year and 5 modules (45 ECTS) and a thesis (15 ECTS) in the second year. The program makes extensive use of the professional experience and environment of the stu- 
dents (Van der Meer \& Ringeling, 2009) and utilizes a number of instruments and methods for reflection (see below).

To picture the way reflection is integrated in the program and gain insight in how this works, one of us held in-depth interviews with 16 of the 20 colleagues teaching in the programiii, asking them what they do in their courses with respect to reflection, which limitations they meet, which results they get, etc.

The results of the interviews can be summarized as follows:

- Almost all courses pay attention to 'really' understanding the theories presented (number 1 in table 1). A large part of the lecturing is, next to summaries of theories, devoted to elaborating and illustrating their rationale and use, and to some extent their presuppositions (table 1, nr. 14)

- Other aspects of reflectivity, except with respect to own functioning and learning reflectivity (table 1, nr. 2-11), are explicitly addressed in one or more modules.

- The remaining aspects of reflectivity (table 1, nr. 12 and 13) and the aspects of reflexivity (nr. 14 - 30) are only addressed incidentally, apart from, to some extent, in the first (20, 22-25), and last two modules of the program.

- A diversity of working methods is used to discuss and practice the forms of reflection mentioned above (see table 2).

- There is no clear plan for (learning) reflection on the curriculum level, i.e. teaching staff tends to use foci and methods that seem to fit well in their own module, with little explicit co-ordination with what is done elsewhere in the curriculum.

- Assessment with respect to reflectivity (except nr. 12) takes place in open exam questions and paper assignments. Reflexivity is hardly assessed, although staff impressions of student abilities in this respect appear to play a role in the marking of final theses.

\section{Working methods}




\begin{tabular}{|l|}
\hline Students formulate their own definitions and theories (first module) \\
\hline Asking questions to students about meaning, presupposition or application of theories \\
\hline Presentations by students \\
\hline Feedback on assignments and presentations \\
\hline Discussing cases (from own practice) in small groups of students \\
\hline Discussing normative and ethical questions \\
\hline Confronting students with alternative interpretations \\
\hline Confronting students with different cases, data, results \\
\hline Demonstration of reflective and occasionally reflexive practice by teaching staff \\
\hline Debate with practitioner guests \\
\hline Inter-vision groups \\
\hline Social simulations and exercises, combined with reflexive evaluations \\
\hline Thesis seminars (small groups) \\
\hline Design of research and intervention strategies by students without a given format or \\
\hline Defending the thesis \\
\hline
\end{tabular}

Table 2: Working methods for reflection

It can be concluded that time and effort is devoted to different forms of reflection and some are even never addressed. The distribution over the different modes and objects seems to be unbalanced and not well coordinated. Moreover there is no clear cumulative line of development with respect to reflection in the curriculum. This picture is somewhat disappointing, since in our view all forms of reflection in table 1 are essential for professionals functioning at an academic level and since teaching staff observes students to lack reflexivity skills in the final stage of the study. 
Before developing options for improvement, it is useful to analyze the factors that produce this state of affairs

\section{Limiting and complicating factors}

Based on the interviews and our own experiences we see the following factors and mechanisms that counteract more balanced, more cumulative and more effective training in reflection. We hypothesize that some of all of these factors also play a role in similar programs elsewhere.

Firstly, almost all teaching staff said in the interview to experience little time to devote attention to reflection in their courses, especially with respect to reflexivity. The knowledge they are expected - or expect themselves - to deliver, tends to occupy almost all time available. Sometimes some forms of reflectivity (especially with respect to understanding and applying theory) or reflexivity (presuppositions of theories) are seen to be useful in the framework of effective knowledge transfer. But in most modules teaching staff doesn't see room for other forms of reflection.

Reflexive questions that we can ask ourselves are: Why do we put this emphasis on knowledge transfer if we doubt whether students become reflexive enough to use the knowledge in sensible and thoughtful ways? Is knowledge transfer by definition concurring with time for reflectivity and reflexivity or are there strategies to combine them? Are there more effective ways of transferring knowledge than by lecturing so that we can use our faceto-face contacts with students in other ways?

The second factor we identified concerns expectations and attitudes of students which often appear to be quite instrumental. This may be related to preceding, more instrumental education and/or to the type of professional functions they occupy. Many students anticipate getting a more advanced toolbox and training to use the instruments in the toolbox in order to be able to function more effectively and on a higher level in their professional practice. They are, at 
least initially, looking for 'the right answers', straightforward do's and don't's. (Van der Meer, 2008). It may be due to this instrumental nature of the students that the teaching staff is convinced that students do not engage in reflexivity on their own account. It may also be that due to this instrumental nature students do not understand what we mean, feel uncomfortable or are even reluctant to engage in reflexivity if we try to force them to do so during contact hours. Although this picture is somewhat too negative if we look at the whole group of students, it seems accurate for a considerable part of it.

Reflexive questions we should ask ourselves are: How is our management of expectations during intake and admission to the program and how can this be improved? How do we (theoretically) explain to the students what reflexivity is and why it is important? How do we make them feel comfortable with reflexivity? And when we create sufficient expectations in this respect, do we follow up these in recognizable ways afterwards? How well are the requirements with respect to critical attitude, reflexivity, translation competences etc. reinforced or contradicted by what we do and ask, especially in the first phase of the program? Do we offer enough unstructured or ambiguous cases and assignments that force students towards reflexivity? How explicitly, how clear and how effective is our feedback to the students if reflexivity requirements are not met?

A third problem is that the number of students in the group (45-70) makes it difficult to actively engage all of them in reflective and reflexive discussions, socratic questioning etc. Teaching staff reports that always the same students are actively participating. Some qualifications may be made in this context. Certainly part of the students not speaking up in plenary sessions are still participating. Looking at their papers and at participation in smaller group sessions some of them are at least as reflexive as the verbal active students in the larger group. Moreover, in small group exercises in reflective/reflexive activity almost all students actively participate. Still, formulating own ideas and arguments helps in making these explicit and reflect on them. Questions are: How can we realize more participation in plenary discussions without dysfunctional repetition and without losing reflective/reflexive depth? Can we 
use more frequently small group work to enhance participation? How can we improve paper assignments and feed-back with respect to reflexivity?

Fourthly, related to the third problem, some students can be observed to be fond of debate, but at the same time to have difficulties with focusing on specific questions or using specific concepts or theories. Moreover normative and analytic elements in the debate are often confused or not well distinguished. Thus, debate as such may hamper the (type of) reflection intended. Here skills of the teaching staff to structure and moderate a discussion in view of its intended focus seems to be vital.

Fifthly, there is a paradox with respect to professional experience students have. On the one hand, having relevant professional experience could facilitate reflection on e.g. theories or strategies, because the latter can be translated to or confronted with empirical phenomena. On the other hand, our experience is that many students have great difficulties in considering their own practice (and their own professional behavior), as well as the self-evidences embedded in these, with critical distance or from a specific perspective. In the first module of the program we do some 'unfreezing' with respect to fundamental concepts like 'government', 'societal issues', '(public) organization and management' and 'science'. But a critical question to address is how we help to realize such 'unfreezing' (deconstruction, creating distance) in the remainder of the program. Since many students write a final thesis on a topic directly related to their own professional practice, this is frequently a big problem in the final stage of the curriculum. How do we deal with this? And how do we facilitate that real-life experience helps reflectivity and reflexivity instead of hemming it?

Finally, the structure of the curriculum as we designed it, may limit the time and attention that can be given to (learning) reflection. As implicated by the first point mentioned above, most staff members give priority to delivery of content and see only limited possibilities to engage their students in reflection. To what extent is it a consequence of the structure of the curricu- 
lum, requirements and norms for exams, the time available per module, the amount of literature to be studied, et cetera? Or, alternatively, to what extent is it related to attitudes or competences of teaching staff?

\section{Options for improvement}

Since a majority of students is not used to reflection, and does not expect and/or is reluctant to be involved in forms of reflection identified in section 2 above, it is necessary to create conditions that will help them in learning and understand the importance of reflectivity and reflexivity, if the learning goals of the program are to be realized. In this section we discuss a number of such conditions we think relevant for optimal teaching and learning of reflectivity and reflexivity in post-experience MPA programs. These conditions overlap and may mutually reinforce each other.

Staff vision and commitment. Teaching staff committed to give attention to certain modes/foci of reflection, having and applying ideas and skills to stimulate and support students to engage in it and including reflection aspects in their assessments and feedback, will help students to learn reflection. This may require less emphasis on delivery of content and more on learning to learn, elaborating materials and reflecting on it in different modes. To realize courses will have to reorganized partly, new didactical methods need to be introduced or tailored to reflection and teachers may need to learn and practice new modes of teaching and moderating.

Management of expectations. Next to the commitment, skills and attitude of the teaching staff, the expectations and attitude of students themselves are an important condition. How can these be influenced? We think it important to communicate from the beginning the critical, researching and creative attitude that is required in public management and hence ex- 
pected from graduates of the academic program. Students should become aware and convinced of this. Box 1 describes how we presently try to contribute to this attitude.

In our program we start with a module called "Exploration”, in which students are asked to formulate what they think and know about the role and task of government, the definition and solution of societal problems, the role and problems of organization and management and the role, status and function of (public administration) science. In the following moderated discussions they discover that

- it is not so simple to answer these simple questions;

- they give other answers than other students (or teachers);

- answers give rise to new questions that often are even harder to answer.

So they are forced to be critical on what seems to be self-evident. They get the feeling that an account, a theory, a set of concepts refers to one way of viewing 'reality' but that there are other perspectives too. Some students renamed the module "Confusion" since it generated more questions than answers. This is what we hoped it would do. By the end of the module students have to formulate their own personal agenda for the rest of their study. Just to make clear that they - and not the teaching staff - are the manager of the learning process. They have to be active, critical, guiding (which is not to say that teachers should not have these characteristics).

Box 1: management of expectation in the first module

Management of expectations does not only refer to the initial stage of the program. On the contrary, if the need for reflection and reflexivity is not made visible and felt again and again, the danger is that students regress to the expectation pattern they had when they entered the program. Of course, in these other modules not only ideas and experiences of students are used as starting points, but theories, methods, cases, guest lectures by practitioners, etc. But in the design of the modules the ongoing learning of reflection should be incorporated. This learning process may be reinforced by the nature and content of the feedback given on papers, 
presentations, discussions, etc. The following two conditions may help to realize a consistent ongoing management of expectations.

Less structured exercises and assignments. As said in section 2, reflection, and especially reflexivity are important for academic PA professionals because many phenomena and problems in their working field are multiple and ambiguous. This argument can be reversed. If reflexivity is to be learned and practiced, teaching needs to create situations (discussions, exercises, assignments) that can be considered from different perspectives and are ambiguous in nature. Therefore, at least part of the assignments need to be not well structured: students should have to 'invent' how they will tackle the assignment, 'translate' theoretical notions to (ambiguous) empirical data and be reflexive on what the results may 'mean'. This means that such assignments have no 'good' answers. They require reflectivity and reflexivity. Staff should, for these assignments, resist pressure of students to 'be clear about what should be done to get a high mark' and be prepared to discuss comments and marking afterwards. In marking, arguments should get more weight than conclusions, creative ideas more than reiterating standard concepts. Also parallel assessment by a colleague may be necessary to arrive at reliable marks. Finally extensive substantive feedback to the student is essential.

Effective use of face-to-face contacts. Learning reflectivity and reflexivity takes time and requires critical (reflexive) feedback. Therefore, it seems important to spend a considerable amount of the time in classes to it. This implies that mere lecturing should be reduced. Although lecturing remains, of course, important for explanation and also to show forms of reflection, part of knowledge transfer (basics of theories, information on cases, guidelines for the application of methods) should take place by means of reading (McKeachie \& Svinicki,2006: 30-34), on-line lectures and the like. ICT and internet technology offer enormous new opportunities in this respect. The lecture time saved can be used for debate and exercises focusing on reflection and for giving peer and teacher feedback to that (McKeachie \& Svinicki,2006: 35-73; cf. also table 2). Of course this only works if students prepare classes 
well (reading texts, doing assignments, et cetera) and are actually presentiv to engage in the interaction with peers and lecturer (Cf. Cramp, 2008), and if they read their text and view the online presentations, etc. in advance.

Staff inter-vision and training. To enhance teaching staff competences and skills to help students to engage in reflective and reflexive thought and practice, they have to be reflexive with respect to their teaching. Training in new ways of teaching and activating students can broaden their repertoire and help them to create reflective and reflexive dialogue during classes. Also teaching staff can observe each other during reflection oriented classes and give each other feed-back (or ask each other for help) on the way they do it. Such a practice may not only improve the quality of teaching reflection, but also contribute to staff dedication and commitment to it.

Diversity and comparison. Confrontation of different perspectives and interpretations help to develop new ideas and to become critical with respect to notions considered self-evident. In post-experience MPA programs, students can be asked to look at each other's problems, policy fields, organizations, challenges. Differences between insider and outsider perceptions, diagnosis, explanations, solution strategies etc. may shed light on ambiguity and alternative interpretations and hence trigger reflexivity. Or they can be asked to apply theories, methods or their own ideas to comparable cases in other countries or policy areas. What are the differences? How are these to be explained? This practices may help to view the own situation in new ways, develop alternative problem definitions and new strategies.

Make students responsible for their analysis. The notion of multiple interpretations of the same situation or problem may give students the idea that it does not matter from which perspective they collect data and analyze them. However, this is quite an unreflexive attitude. Although there is not an unequivocally 'correct' perspective, academics should be able to justify the perspective(s) they use. It is their choice, and students should be asked to defend this. 
Especially when they have to present their analysis, conclusions and advice to practitioners involved (peer students or external actors) they may be forced to explain and discuss their choices and interpretations. Anticipating such dialogue may make them reflexive and responsible in advance (Weinstein, 2006). The way assessment is organized and shaped should reinforce taking responsibility and being reflexive (Gibbs, 2006). So if students only refer to what 'authorities' or 'experts' say and do not articulate and defend their own choice of questions, sources, arguments, analyses, conclusions and advice, they should not get high marks.

Organize teaching and learning reflection at the curriculum level. The review of our program at Erasmus University showed that almost all teachers do pay some attention to some form(s) of reflection, but not in a coordinated way. Since it is also clear that it is not possible (nor desirable) to devote attention to each form of reflection in all modules, it is important to develop some sort of scheme for the curriculum as a whole. Based on table 1 above, such a scheme could plan which mode(s) and which focus/foci of reflection are (at least) to be addressed in which module. Of course, such a plan should be flexible and be made in a reflexive mode: which type(s) of reflection can in what way be (best) focused on by which teacher in which module? This, again, requires reflexive dialogue within the teaching staff, ex ante and ex post. 


\section{A strategy for improvement}

Now, the options discussed in section 4 may be sensible and attractive, but that does not imply that their implementation is easy or straightforward. To expect so, would in fact be quite unreflexive. As noted in the first point in section 4, teaching staff vision and commitment is of utmost importance for training in reflection to be successful, and, connected to that, the preparedness of staff to invest in developing necessary skills and competences. Therefore a strategy to involve teaching staff in the development of 'teaching reflexivity' is as important as the other ideas discussed in section 4 . In the present section we outline the strategy that we apply and intend to apply in the Rotterdam program (presently we are about to start the fourth step). We think this approach may be useful for other similar programs as well.

Step 1: inventory of current practices and problems with respect to reflection. This is in fact what we reported on in section 3 . This step gives an overview of the building blocks, commitments and competences that are already available. It also gives an image of the problems to be tackled. Moreover it tempts staff to think about reflection and to make explicit what they do, why, which problems and what limitations they experience, etc. Apart from information gathering, this may be a first step in building commitment. Both outcomes can be enhanced by also asking for suggestions to improve the reflection part of the program. In fact, a number of the ideas in section 4 emanated from such suggestions.

Step 2: report the results back and discuss them. This gives the staff an impression of what their colleagues do and on what is (not) done in the curriculum as a whole. It may provide them with new ideas about what they can do themselves, but also what is missed in the program. Discussions among the teaching staff may generate new ideas and plans. 
In a staff session about our program we reported the results as described in section 3 . This gave rise to a number of interesting and useful discussions, such as the following.

- There was a general feeling that more time and attention for reflection is very desirable, although some doubt whether that is really possible.

- The idea to think about more efficient ways to transfer knowledge, occupying less time during classes, was supported.

- The idea to make a plan for reflection on the curriculum level was supported.

- New ideas were generated, especially with respect to students visiting each other's organizations, solving each other's problems, etc.

- Staff picked up ideas from each other to create time and conditions for reflection

- Ways should be found to integrate reflection in assessment

In such a session commitment and thinking with respect to reflection may be further stimulated as well.

Step 3: develop a plan on the curriculum level focusing on answers to the following questions.

o How can teaching and learning reflection be integrated in the different modules

o How can distribution of attention for different types of reflection over the modules be realized and accumulation in the program as a whole be shaped?

o How to assess different forms of reflection?

The framework of table 1 can be used as one of the tool to develop this plan.

Step 4: discuss this plan in a staff meeting. In this session the rationale behind the plan is presented and discussed. The discussion may lead to adaptations, since general support and commitment of the teaching staff is essential in this stage. They should not only agree, but also find it attractive to invest in their own contribution to the plan. 
Step 5: offer training and stimulate inter-vision. Teaching staff have different experience and expertise in helping and stimulating students to engage in the different forms of reflection. Especially the reflectivity aspects 8-13 and the reflexivity aspects 20-30 (table 1) are not always included in academic teaching. Therefore some staff members may lack ideas and tools to do so. By inter-vision staff members can learn specific teaching forms and strategies from each other in this respect. Nowadays new staff members usually get courses in teaching. It seems useful to include teaching reflection in such training.

Step 6: regular joint evaluations and discussion about further improvement. Evaluation of the impact of the steps discussed above on the different forms and modes of reflection is useful to think of new options to improve teaching and learning reflection. By involving the teaching staff in this evaluation process they can contribute from their experiences and become involved in the development of further improvements, which may enhance the saliency of teaching reflection and their commitment to engage in it.

\section{Conclusion}

Reflection, both in the sense of reflectivity and of reflexivity, is essential in post-experience MPA programs since such programs aim to educate professionals able to deal with complex problems, uncertainty, ambiguity and a multiplicity of problem definitions and actor perspectives. Reflection should not only focus on theories and methods taught, but also on problems in the (own) field and practice of students, on what are to be considered solutions or sensible strategies and why, on professional functioning and on reflection itself.

This chapter identified a number of complicating factors, options to overcome them, and outlined a strategy to involve teaching staff in the process of making more reflection oriented 
programs and develop a viable practice of teaching reflectivity and reflexivity. In combination these elements may help to realize a setting in which students are learning to reflect in the different modes and with respect to the different foci discussed, and to develop an attitude in which reflectivity and reflexivity are key ingredients of their professional self-definition.

\section{Discussion}

The paper has addressed how teaching staff and the MPA program at curriculum level can be adjusted to promote reflection in the program. However, it is not completely clear what the reasons may be that students find it difficult to develop reflective skills. We have not gone into the psychology of the students, but teaching staff experiences a lack of willingness, lack of knowledge, and/or lack of understanding in students for developing reflective skills. Besides the way to communicate what we expect the students to achieve and provide the teaching material for appropriate learning, it may also be that it is necessary to demonstrate the practical usefulness and importance in order to develop this understanding, like we do in the first course (exploration) of the program. Extra research creating information on the reasons why students have problems learning reflective skills may be a useful addition and can strengthen the strategy set out in this paper.

\section{Acknowledgements}

The authors would like to thank Hanne Knudsen, Hanne Adriansen, Monika Knassmüller and Renate Meyer for their comments on earlier drafts.

\section{References}

Adriansen, H. K., \& Knudsen, H. (this special issue). Two ways to support reflexivity.

Adriansen, H. K., \& Madsen, L.M. (2009). Studying the making of geographical knowledge: The implications of insider interviews. Norwegian Journal of Geography, 63, 145-153. 
Cramp, A. (2008). Developing student engagement with, and reflection on, feedback through the tutorial system. In A. Wheeler (Ed.), Learning and teaching projects 2005-2007 (pp. 211-220) Institute for Learning Enhancement, University of Wolverhampton.

Cunliffe, A. L. (2002). Reflexive dialogical practice in management learning. Management Learning, 33(1), 35-61.

Cunliffe, A. L., \& Jun, J. S. (2005). The need for reflexivity in public administration. Administration \& Society, 37(2), 225-242.

Gibbs, G. (2006). How assessment frames student learning. In C. Bryan, \& K. Clegg (Eds.), Innovative assessment in higher education (pp. 23-36). London, New York: Routledge.

Gur-Ze'ev, I., Masschelein, J., \& Blake, N. (2001). Reflectivity, reflection and counter-education. Studies in Philosophy and Education, 20, 93-106.

McKeachie, W. J., \& Svinicki, M. (2006). McKeachie's teaching tips: Strategies,research and theory for college and university teachers (12th ed.)

Meer, F. B. van der (2008). Interaction between demand and supply in mid-career PA teaching. Paper EGPA-conference.

Meer, F. B. van der (2010). Learning reflection in MPA programs. Paper Workshop of the European Pedagogical Group on MPA Programs, Copenhagen 
Meer, F. B. van der, \& Ringeling, A. B. (2010). An education strategy for practitioners in public administration master's programs. Journal of Public Affairs Education, 16(1), 77-93.

Meer, F. B. van der, Ringeling, A. B. (2009). Study and work experience: Delinking and relinking. In C. F. Bonser (Ed.), Adapting universities to the global society a trans-atlantic perspective (pp. 65-81). Berlin: LIT Verlag.

Quinn, B. (this special issue). The reflexive public manager.

Smith, E. (2011) Teaching critical reflection. Teaching in Higher Education, 16(2), 211-223.

Weinstein, C. E. (2006). Teaching students how to become more strategic and selfregulated learners. In W. J. McKeachie, \& M. Svinicki (Eds.), McKeacie's teaching tips: Strategies, research, and theory for college and university teachers (pp. 300-317). Boston, New York: Houghton Mifflin Company.

i Other authors use similar terms in other ways, which may create some confusion. E.g. Gur-Ze'ev et al (2001) use 'reflective' as Jun \& Cunliffe do, but use 'reflection' for what Jun \& Cunliffe refer to as 'reflexivity'. We follow Jun \& Cunliffe, but use 'reflection' as the general concept, comprising both reflectivity and reflexivity. Jun \& Cunliffe use 'reflection' as synonymous with reflectivity).

ii This and other statements about students' difficulties and inclinations are based on our own observations and those of our colleagues we interviewed. We plan to investigate student perceptions and experiences on these points.

iii See Adriansen \& Madsen (2009) for some methodical aspects of interviewing colleagues. iv In our program students have to be present at least $80 \%$ of the sessions. 